УДК 616.718.19-006.33-089.87(045)

DOI: http://dx.doi.org/10.15674/0030-5987201745-14

\title{
Conceptual strategy for pelvic resections in tumor patients
}

\section{O. E. Vyrva, R. V. Malyk, Y. O. Golovina}

Sytenko Institute of Spine and Joint Pathology National Academy of Medical Sciences of Ukraine, Kharkiv

Pelvic resection is a technique that involves surgical resection of portions of the pelvic girdle. Hemipelvectomy is a pelvic resection that salvages an ipsilateral limb. The main indication for these procedures is primary malignant tumors of the pelvis (mostly chondrosarcomas), but in rare cases they are indicated for metastatic lesions, infection, or trauma. Objective: the main purpose of this study was to analyze pelvic resection patients. Methods: the results of treatment of 239 patients (131 male and 108 female) with pelvic tumors who were undergoing surgeries procedures in the Sytenko Institute from 1963 till 2017 were evalueted. 186 patients were operated at modern era in 2004-2017. The most frequent nosologies were chondrosarcomas, osteochondromas and secondary metastatic lesions. The average age of patients was (37.2 \pm 18.9$)$ years (7-80). Preoperative planning is crucial to define the extent of the tumor, plan the surgical margins, and identify the location of the vital structures. Necessary imaging includes plain radiography, CT, and MRI. There were 38 patients with type I resection (by Enneking and Dunham classification), 132 - with II type and 69 - with III type resection in our series. Results: reconstruction is dictated by the extent of the resection and the remaining structures. Surgical technique is dictated by histology of the tumor and location of the lesion. Allograft and autograft pelvic reconstruction has been used for patients. The TESS and MSTS have been applied to assess function outcomes. Wound infection and flap necrosis, nonunion, nerve palsy and local recurrence of malignant tumors are the most common complications for hemipelvectomies and pelvic resections. Conclusions: a multidisciplinary team is required for treat bone tumor of a pelvis. Appropriate preoperative counseling with the patient and family is paramount to explain the magnitude of the procedure, common complications, and predicted functional loss. Key words: pelvic resection, hemipelvectomy, bone tumors, surgical procedure.
Резекиия костей таза предполагает удаление различных по объему и локализачии участков тазового кольца. Изначально гемипельвэктомия включала сохранение ипсилатеральной с пораженной стороной таза конечности. Основными показаниями являются первичные злокачественные опухоли таза (чаще - хондросаркомы), иногда - метастатические поражения костей, инфекиии и т. n. Цель: проанализировать результаты хирургического лечения пацчиетов с опухолями таза. Методы: оценены результаты лечения 239 пациентов (131 мужчина, 108 женщин) с опухолями таза, прооперированных за период 1963-2017 г2., 186 - за последние 13 лет. Средний возраст пациентов $(37,2 \pm 18,9)$ лет (от 7 до 80). Наиболее частые нозологии: хондросаркома, остеохондрома, метастазы. Пациентам проведено комплексное обследование, в том числе гистологический анализ биопсийного материала, МРТ, КТ. Резекияи I типа по классификаиии Enneking и Dunham произведена 38 больным, II - 132, III - 69. Результаты: план хирургического вмешательства определялся гистологическим характером опухоли и локализацией патологического очага. Замещение удаленных сегментов таза, как правило, было обусловлено объемом резекичи и стабильностью оставшейся части тазового кольиа. Использовали аутои аллотрансплантаты. Результаты хирургического лечения пациентов оценивали с помощью шкал TESS и MSTS. Среди осложнений лечения были глубокие инфекиии, некрозы кожно-мымечных лоскутов, несращения костных трансплантатов, нейропатия нервов с парезом стопы, речидивы опухоли. Выводы: для разработки общей схемы лечения необходим мультидисциплинарный подход с привлечением необходимых смежных спечиалистов. Очень важным моментом перед проведением подобных операчий является обязательное ознакомление пациента и его семьи с характером вмешательства, особенностями опухолевого процесса, возможными осложнениями, прогнозируемой продолжительностью и качеством жизни после операции. Ключевые слова: резекиия таза, гемипельвэктомия, опухоли костей, хирургическое вмешательство.

Key words: pelvic resection, hemipelvectomy, bone tumors, surgical procedure 


\section{Introduction}

Pelvic resection and hemipelvectomy are rare procedures that are used primarily in management of primary malignant tumors but also, in management of metastatic tumors, severe trauma, infection. One goal of pelvic resection is limb salvage of the ipsilateral lower extremity. This procedure involves local resection of all or portions of the involved hemipelvis.

Hemipelvectomy is a more ablative procedure in which the involved hemipelvis is removed in its entirety, along with the ipsilateral extremity. This procedure is also known as hindquarter amputation. The first reported hemipelvectomy was performed by Billroth in 1889, the procedure was unsuccessful. In 1895, Billroth's contemporaries Jaboulay, Caciopoli, and Girard performed the first successful hemipelvectomy [1]. In 1909, Ransohoff [2] became the first surgeon in the United States to complete the hemipelvectomy successfully.

Limb salvage via pelvic resection marked a significant advancement in the management of pelvic neoplasms. Eilber et al. [3] were among the first to establish pelvic resections as an alternative to hemipelvectomy.

With proper patient selection and surgical technique, survival and recurrence rates are no worse for pelvic resections than for hemipelvectomy. Enneking and Dunham [4] developed a classification system for pelvic resection based on the section or sections of bone to be resected (ie, iliac, periacetabular, pubic) and the degree of resection (wide or radical) (fig. 1). Early pelvic resections did not involve pelvic reconstruction and often left patients with poor functional outcome. Advancements in flap coverage techniques and megaprostheses have facilitated pelvic reconstruction and improvements in functional outcomes following limb salvage, although often at the expense of a higher incidence of complications.

The true incidence of hemipelvectomy in the United States is unknown. However, it has been estimated to be approximately 1 per 1 million annually [5]. Unfortunately Ukrainian statistic data in general is unknown.

Primary bone tumors. Among all cancers, primary bone tumors account for $<0.2 \%$ of all cases and mostly afflict patients aged $<20$ years or between 40 and 50 years [6]. In the United States, the annual incidence of primary bone tumors is approximately 2500 , with annual mortality of approximately 1400 . Approximately $15 \%$ to $20 \%$ of all primary bone tumors are located in the pelvis. The three most common histologies are osteosarcoma (35\%), chond- rosarcoma (30\%), and Ewing sarcoma (16 \%) [6]. Malignant fibrous histiocytomas and fibrosarcomas account for $<1 \%$ of all primary bone tumors. Osteosarcoma and Ewing sarcoma most commonly occur in childhood. In the United States, an estimated 650 to 700 malignant bone tumors are diagnosed each year in children aged $<19$ years, of which $54 \%$ are osteosarcoma and $35 \%$ are Ewing sarcoma. Five percent of osteosarcomas occur in the central axis, whereas $45 \%$ of the cases of Ewing sarcoma occur in the central axis. Chondrosarcomas occur more frequently in older adults [6]. Fewer than $20 \%$ of all primary bone cancer cases present with metastatic disease at diagnosis. Cases of metastatic cancer are best suited to aggressive surgical resection because they have the potential for cure.

Primary soft-tissue sarcomas. Approximately 10000 cases of soft-tissue sarcoma are diagnosed each year in the United States, and the annual overall mortality rate is approximately 3800 per year [7]. Overall, sarcomas comprise $<1 \%$ of all adult and approximately $15 \%$ of pediatric malignancies. Approximately $5 \%$ of all soft-tissue sarcomas are located in the pelvis [6]. Depending on the clinical presentation, soft-tissue sarcomas rarely require bony resection or amputation. The most common sites are the extremities $(60 \%)$, trunk $(19 \%)$, retroperitoneum (15\%), and head and neck (9\%) [7]. Metastases are most likely to arise in the lungs, whereas sarcomas arising in the abdominal cavity are more likely to have metastasized to the liver. The local recurrence rate is $15 \%$ to $20 \%$, with a 5-year mortality rate of $50 \%$ to $60 \%$ for high-grade lesions [7].

Metastatic tumors and hematopoetic malignancies. Pelvic skeletal metastases are most commonly due to cancers of the breast, lung, prostate, kidney, and thyroid; other primary sites include the colon, rectum, uterus, and endometrium [8]. Metastasis due to breast and renal cancer is the type that most commonly requires surgery. Hematologic malignancies seen in the pelvis include lymphoma and myeloma. Most metastatic lesions of the pelvis can be readily managed with radiation and pain control [9]. If pain is not controlled or if mechanical weakness persists, local curettage with cement or limited reconstruction typically is effective if the defect is contained and does not involve the hip joint or erosion through the acetabulum. Reconstructions that require complex acetabular reconstruction are beyond the scope of this review.

In general, hemipelvectomy is rarely indicated for palliative intent in the patient with systemic disease. However, it may be considered for isolated 
metastasis in the setting of renal cell carcinoma or a solitary plasmacytoma. One-year survival in patients with isolated bone metasta-sis from renal cell carcinoma is significantly better than that of patients with visceral metastasis, and wide resection may result in prolonged 5-year survival $[10,11]$. If the malignancy encases the neurovascular structures or is seen to be fungating through the skin, more aggressive palliative resection may be required. The morbidity and mortality of the resection, the lengthy rehabilitation process, and limited life expectancy must be thoroughly discussed with the patient and family preoperatively.

Anatomic considerations. The anatomy of the hip and pelvis is complex and challenges even the most experienced surgeon. The bony pelvis is divided into the iliac wing, the periacetabular region, and the obturator ring, which includes the pubic rami. The pubic rami join at the pubic symphysis anteriorly and articulate with the sacrum via the strong sacrotuberous and sacrospinous ligaments. The common iliac artery crosses and bifurcates along the sacral ala. The artery divides into the internal and external iliac arteries and their corresponding veins. The internal iliac vessels exit the pelvis through the greater sciatic notch, and the external iliac vessels exit the pelvis medial to the iliopsoas tendon to become the femoral artery. The ureter crosses near the division of the internal and external arteries from lateral to medial as it passes to the bladder. The major neural structures include the sciatic, femoral, and obturator nerves and their preceding nerve roots.

The iliacus muscle is located on the inner table of the iliac wing. The psoas major muscle originates on the vertebral bodies, traverses the pelvis, and joins the iliacus to form the iliopsoas tendon, which crosses over the pelvic brim en route to its insertion on the lesser trochanter. The femoral nerve runs between these two muscle bellies. The adductor muscle group, pelvic floor muscles, anterior thigh muscles, and posterior thigh muscle all originate from various locations on the pelvis and often require resection depending on the location of the tumor and bone to be removed.

Depending on the specific location of the tumor, vital structures such as the urethra, prostate (in males), corpus of the penis (in males), rectum, and bowel can also be involved or require protection when removing these tumors. In female patients, the uterus, ovaries, and vagina may require removal or protection, as well, depending on the location of the mass.

\section{Matherial and methods}

The main purpose of this study was to analyze pelvic resecion patients in Syneko Institute who were undergoing surgeries procedures from 1963 till 2017. It was group of 239 patients with pelvic tumours. 186 patients were operated at modern era in 2004-2017.

The study was approved by the bioethics committee of Sytenko Institute of Spine and Joint Pathology National Academy of Medical Science of Ukraine (protocol № 169, 17.10.2017).

The most number of patients were with chondroblastic tumors (chondrosarcomas and osteochondromas) and secondary metastatic leasions (table). Gender distribution was male 131 (55\%) and female 108 (45\%). Mean age $-37,2 \pm 18,9(7-80)$ years.

Options for pelvic resection vary greatly depending on the histology of the tumor and the location of the lesion. A thorough knowledge of pelvic anatomy is required when considering surgical intervention for a malignant tumor. Preoperative planning is crucial to define the extent of the tumor, plan the surgical margins, and identify the location of the vital structures. Necessary imaging includes plain radiography, $\mathrm{CT}$, and MRI. A multidisciplinary team is required, and the entire team should review the surgical plan before proceeding. This step will ensure the proactive consideration of all aspects of care, that is, potential neoadjuvant treatments, resection considerations, reconstruction options, and postoperative care, in order to maximize outcomes.

Pelvic resection. Tumors located in or eroding into the bony pelvis often require surgical resection. Most resections are performed with the goal of achieving negative margins (ie, no malignant cells identified at the bone edge). Given the complex anatomy, however, this outcome is often difficult to obtain.

Preoperative imaging is used to define the extent of the tumor, plan margins, and identify the location of the neighboring vital structures. Pelvic resection can be considered when the tumor does not involve the major neurovascular structures such that a functional limb can be preserved without compromising the margins necessary to minimize risk of tumor recurrence. From a functional standpoint, Enneking and Dunham type I and type III resections are superior to periacetabular (type II) resection. Depending on the location of the tumor, a combined resection may be required. For example, a type II/III resection would involve both the periacetabulum and the pubic rami. These combined resections often influence the reconstruction options because there is less bone to work with following resection. 
Table

Nosological distribution

\begin{tabular}{|l|c|c|}
\hline \multicolumn{1}{|c|}{ Pimary diagnosis } & Abs. & $\%$ \\
\hline Aneurismal bone cyst & 8 & 3.3 \\
\hline Chondroblastoma & 2 & 0.8 \\
\hline Fibroma & 2 & 0.8 \\
\hline Fibrous dysplasia & 8 & 3.3 \\
\hline Giant cell tumor & 10 & 4.2 \\
\hline Osteoblastoma & 2 & 0.8 \\
\hline Osteochondroma & 24 & 10.0 \\
\hline Osteoid-osteoma & 5 & 2.1 \\
\hline Angiosarcoma & 5 & 2.1 \\
\hline Chondrosarcoma & 47 & 19.7 \\
\hline Fibrosarcoma & 3 & 1.3 \\
\hline Malignant lymphoma & 6 & 2.5 \\
\hline Multiple myeloma & 9 & 3.8 \\
\hline Metastatic tumors & 61 & 25.5 \\
\hline Osteosarcoma & 12 & 5.0 \\
\hline Ewing sarcoma & 7 & 2.9 \\
\hline Others & 28 & 11.7 \\
\hline Total number & 239 & 100.0 \\
\hline
\end{tabular}

Hemipelvectomy. Hemipelvectomy for resection of tumors of the pelvic girdle should be considered if pelvic resection cannot be performed with adequate margins or if removal of the tumor will leave a functionless limb. O'Connor and Sim [12] attempted to identify which patients should be treated with pelvic resection and which should undergo hemipelvectomy. The three anatomic structures that must be considered are the sciatic nerve, the femoral neurovascular bundle, and the hip joint (ie, periacetabular region). As a general rule, should two of these structures require resection to obtain an adequate margin, then hemipelvectomy should be considered. Wound closure can be achieved with either an anterior flap or a posterior flap depending on the location of the tumor. Flap selection should be made preoperatively to allow proper planning. It may be necessary to involve plastic surgery experts at the index procedure in cases that would benefit from free flap closure. Figures 2-5 have illustrated a total hemipelvectomy case of chondrosarcoma teenager with good functional result without reconstruction options.

Prostheses are available for use following hemipelvectomy, and the decision to use them is made on a case-by-case basis. During preoperative counseling, the patient should be advised that the prosthesis is difficult to anchor and that it typically requires some combination of waist and shoulder strap. The hemipelvectomy prosthesis requires a great deal of energy expenditure secondary to the swing gait required. Older patients typically do not well tolerate such a prosthesis. Thus, most patients use crutches or are wheelchair-bound [13].

Reconstruction options. Reconstruction of the bony pelvis is considered on a case-by-case basis. Whether to reconstruct the skeletal defect is a complex issue that is fraught with controversy. No strong guidelines exist, and decisions should be individualized to each patient. Certain anatomic resections lend themselves more easily to a functional reconstruction, whereas some are better left unreconstructed. Pelvic reconstruction should be considered for type II periacetabular resections and for combined resections in cases in which the continuity of the lumbopelvic articulation is compromised. In general, options consist of biologic (eg arthrodesis, bone graft), prosthesis, or none.

\section{Results}

\section{Type I resection}

Resection of the iliac wing often is left unreconstructed, with minimal functional compromise. There were 38 patients with type I resection in our series. However, inclusion of the sciatic buttress in the resection results in disrupted continuity of the pelvic ring; this must be restored to preserve limb length. This can be achieved with allograft, autograft (often vascularized fibula), or a metallic prosthesis. In general, outcomes of type I resection are favorable, with most patients regaining independent ambulation.

Beadel [14] performed a case-control study of 16 patients treated with either reconstruction or no iliosacral repair (4 and 12 patients, respectively). The Toronto Extremity Salvage Score (TESS) and Musculoskeletal Tumor Society (MSTS) 1987 and 1993 scores were similar between the groups, and similar rates of local recurrence and survival were noted as well. However, patients who did not undergo reconstruction had a lesser need for ambulatory assistive devices and chronic pain medication. Electing for no reconstruction is a viable option in type I resections. We have got the almost similar follow-up functional results in our group of patients with type I pelvic resection.

\section{Type II resection}

Resection of the periacetabular region is the most challenging type from both a resection and reconstruction perspective. The surgical procedure is associated with the highest complication rate of all the types. A variety of reconstructive options exist.

Resection arthroplasty. The Friedman-Eilber resection arthroplasty, in which the pelvis is left unreconstructed (ie, flail hip), has gained increasing support and popularity. Although this technique 

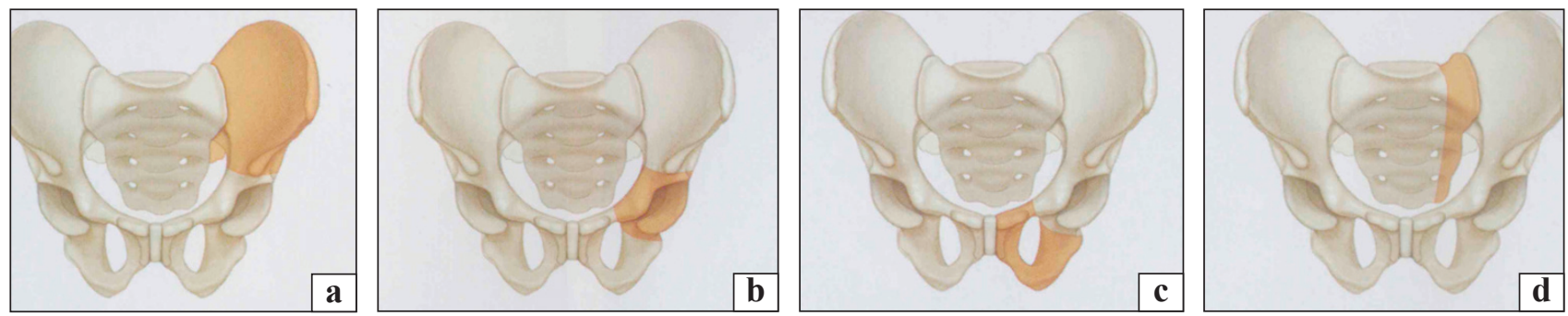

Fig. 1. Illustration of the Enneking and Dunham classification of pelvic resection. Type I involves the iliac wing (a), type II the periacetabular region (b), type III the pubic rami (c), and type IV the sacrum (d). The resections can be combined. For example, a type I/II resection would include the iliac wing and acetabulum. The deep orange area in each type indicates the bony area to be resected
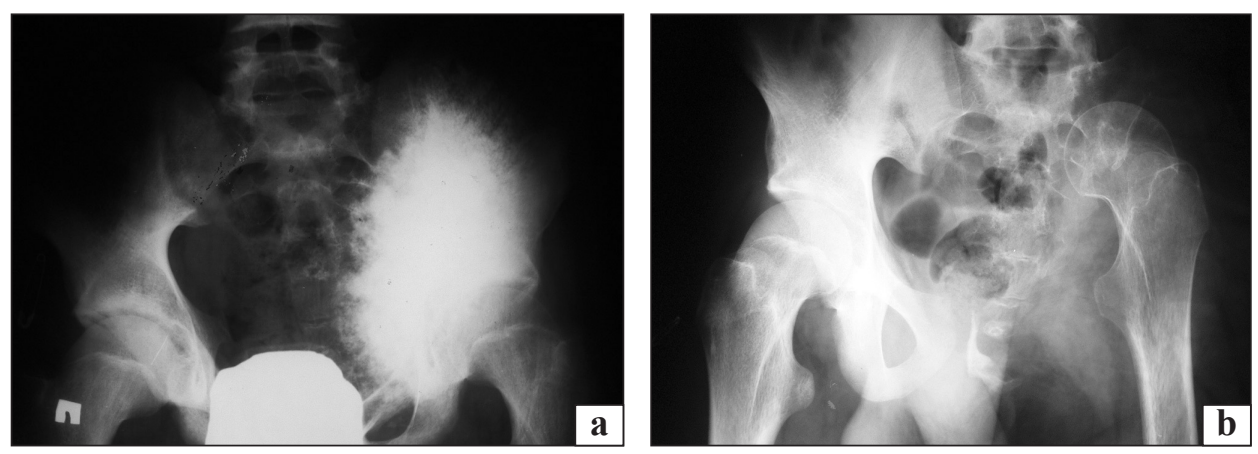

Fig. 2. Illustration of the total hemipelvectomy. Male B., 16 y. o., chondrosarcoma (a); 3 years
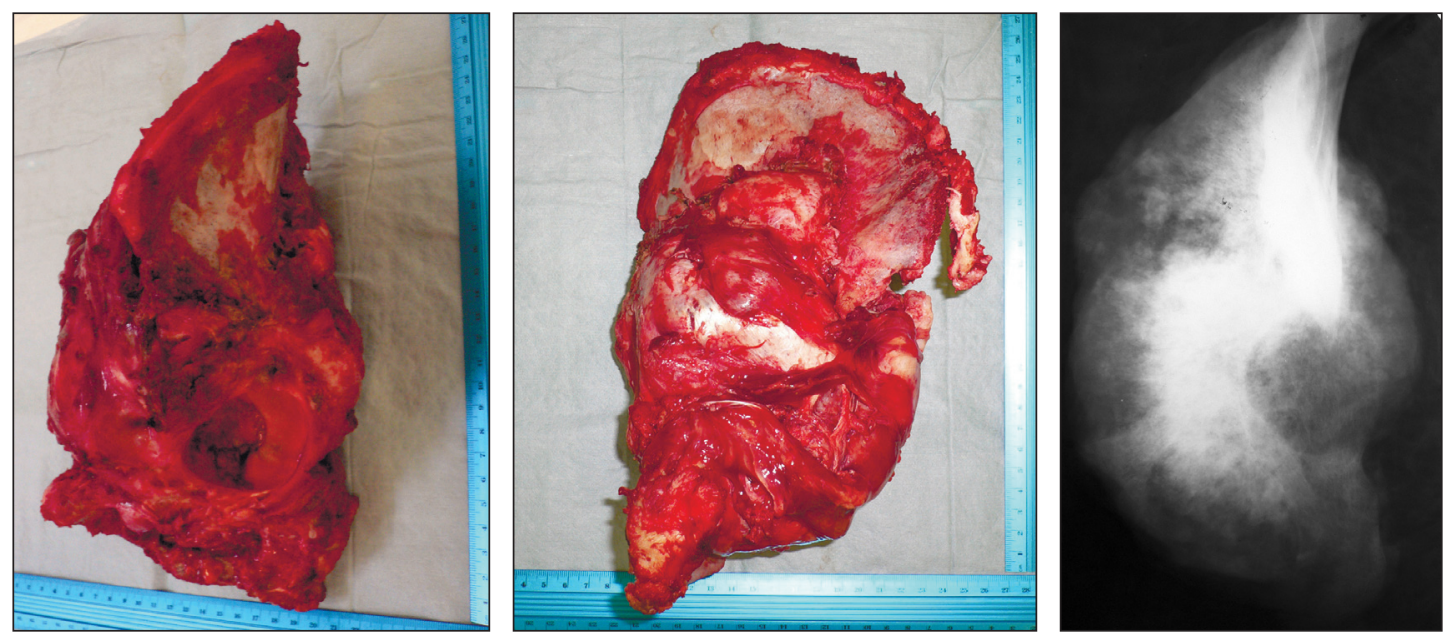

Fig. 3. Illustration of the tumor specimen after total hemipelvectomy. Male B., 16 y. o., chondrosarcoma
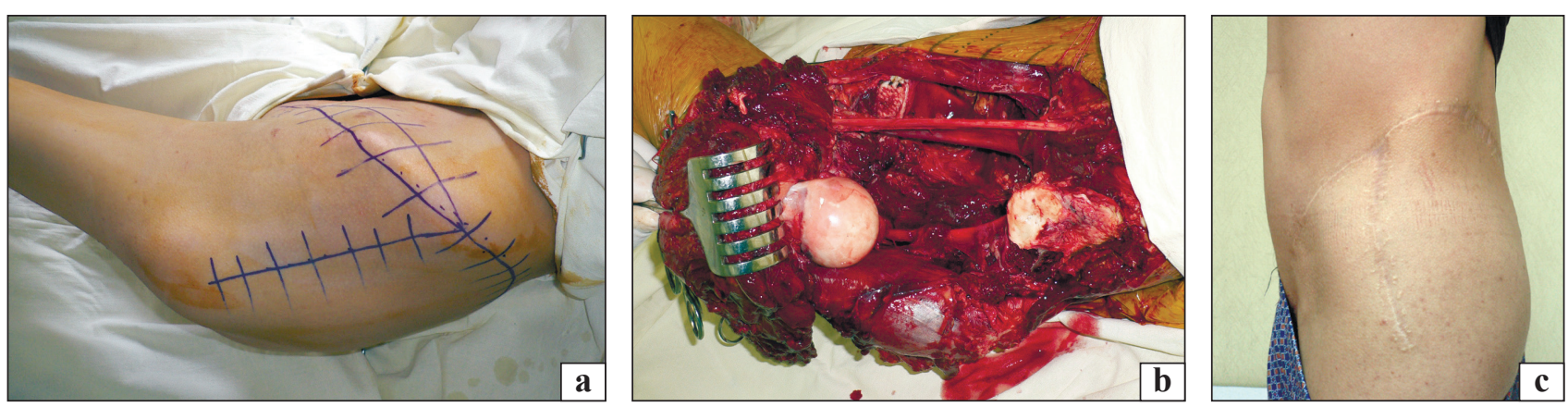

Fig. 4. Illustration of the total hemipelvectomy. Male B., 16 y. o., chondrosarcoma. Planning of surgery approach (a); three anatomic structures: sciatic nerve, femur head and femoral neurovascular bundle (b); 3 years after surgery (c)

has a long recovery time of approximately 2 years, when maximal function obtained, it avoids the high complication rate noted in conjunction with many of the reconstructive options [13]. Complications include infection, nonunion, and neurapraxia. Prior studies have estimated a 30 to $50 \%$ complication rate 

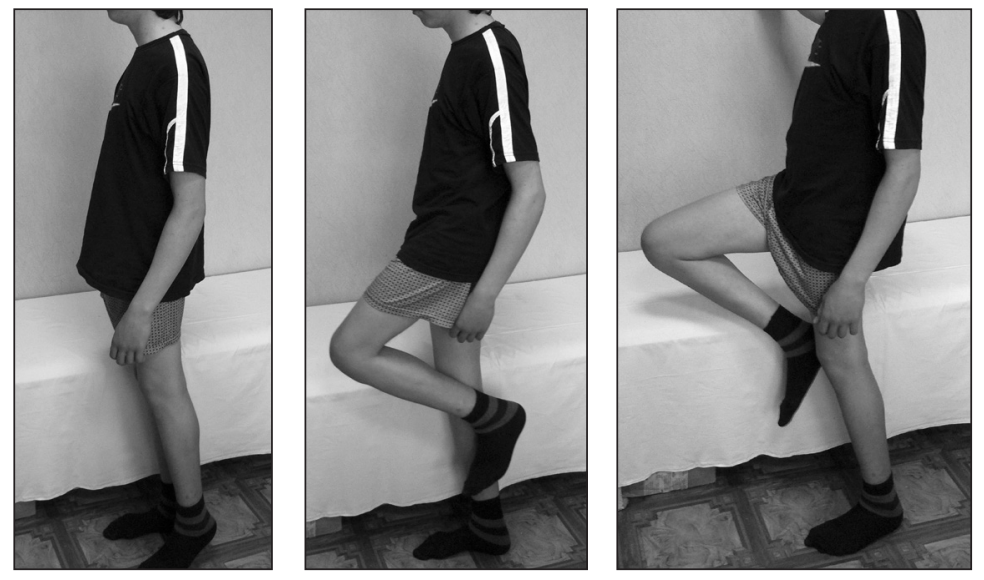

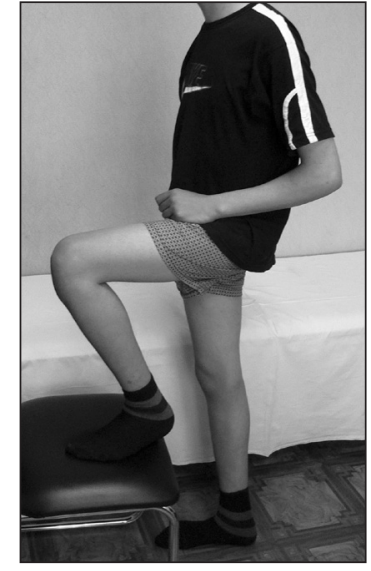

Fig. 5. Illustration of the total hemipelvectomy. Male B., 16 y. o., chondrosarcoma. Functional result 2 years after surgery when resection and reconstruction are performed in one procedure [14]. In contrast, a published case series highlighted outstanding outcomes and unassisted ambulation in seven patients treated in this fashion [15]. The procedure is also associated with shorter surgical time, reduced blood loss, and decreased hospital stays compared with reconstruction.

Depending on the amount of bone resected, the proximal femur or femoral head may be anchored or tied to the remaining ilium or sacrum in a procedure known as hip transposition. Typically, the proximal femur is anchored with transosseous sutures, bone anchors, or Gore-Tex tubing (W. L. Gore \& Associates) [16]. Suspension and stabilization of the residual limb is crucial to maximize function and provide some stability. We have analized 84 patients with just resection arthroplasty type II resection and it was most common and most complicated type of surgery (fig. 6).

The complications following resection arthroplasty are wound complications and nerve palsies. Typically, the nerve palsies are peroneal in nature. Very few of these complications require further surgical intervention. Thus, a major advantage of this method is that it markedly diminishes the risk of subsequent surgeries associated with prosthetic or allograft complications or infection.

Saddle prosthesis. The saddle prosthesis was designed to maintain leg length in patients undergoing periacetabular resection. The prosthesis is anchored in the femur in a manner similar to that used in conventional total hip arthroplasty. An articulation notch is made in the remaining ilium, and the proximal prosthesis hinges over this notch [17]. Reconstruction with a saddle prosthesis is associated with substantial morbidity, with high rates of infection, nerve palsy, dislocation, fracture, device migration, and heterotopic ossification [18]. Benefits of this technique are ease of insertion, restoration of limb length, and modularity of the device. Although some patients achieve an acceptable functional outcome, the indication for this reconstructive option is narrowing because of the high complication rate. There are no cases of saddle-prosthesis reconstruction in our study group. We have done detail analize of published literature data.

Allograft/prosthetic composite. Massive alloprosthetic reconstruction using allograft bone combined with total hip arthroplasty in pelvic resections is an option for periacetabular resection. The recon-
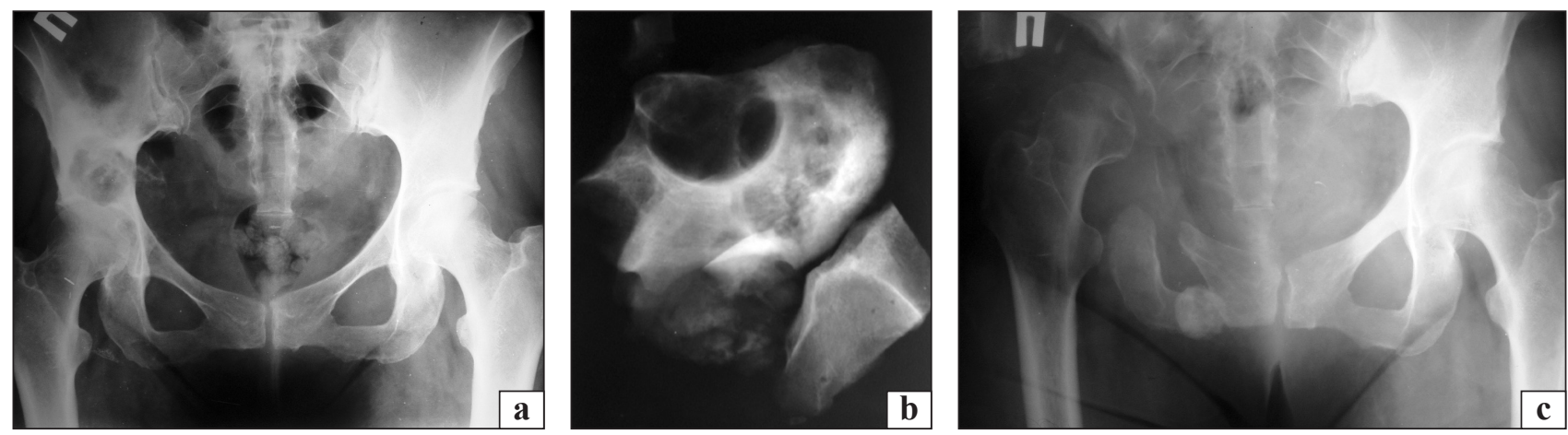

Fig. 6. Illustration of the type II pelvic resection that involves the periacetabular region. Female R., 47 y. o., malignant lymphoma (a); resected tumor specimen (b); 4 years after surgery (c) 
struction is technically demanding but has the ability to preserve limb length and maximize function. Deep infection, nonunion, nerve palsy, and hip instability are seen in almost $50 \%$ of the patients treated in this fashion. However, young patients who achieve union can gain good functional results and restored limb length [20].

Allograft pelvic reconstruction has been used for 48 patients and have had $38 \%$ complacation rate (infection, nonunion and malignant tumor local reccurency).

Custom device. Although several implant companies have the capability to generate custom metallic devices. It is requered FDA approval for individual using in USA. The lengthy approval process has limited the use of custom implants. We have used Kharkiv, Ukraine custom-made implants and it was good quality and not expensive to compare with Europe or US companies. Most of the literature on these devices consists of small series or reports in which this option is combined with various other reconstruction methods [21,22]. Thus, it is difficult to draw conclusions about their efficacy. Loosening and infection are common complications, which limits the use of this option.

\section{Type III resection}

Resection of the pubic rami requires no reconstruction. Most patients exhibit satisfactory functional outcomes and achieve unassisted ambulation.

Combined resections. Depending on the location of the tumor, resection types may be combined (ie, type I/II, type I/IV). The more bone that is resected, the more limited the options for reconstruction (fig. 7, 8). Compared with the resection techniques discussed above, resection arthroplasties perform better and are associated with less proximal migration when a portion of the ilium is left intact. Use of the saddle prosthesis requires an adequate amount of ilium to which to anchor the device. Similarly, allograft-prosthetic composites depend on an adequate foundation of bone on which to place plates and screws to fix the allograft to the host bone. The rest patients in our study series (69 patiens) were operated by type III resection and different combinations of resection types deppending of bone-soft tissue loss after tumor resection.

Compound resection. Resection of abdominal viscera along with the bony pelvis is indicated in rare cases. These so-called compound resections require coordinated care with general surgery, urology, and plastic surgery staff as necessary. Traditionally, such reconstruction has been avoided in these cases because these resections constitute so-called cleancontaminated procedures (ie, class II surgical incisions according to the American College of Surgeons wound classification) and carry a significantly elevated risk of postoperative infection.

Soft-tissue considerations. In any resection, softtissue reconstruction is an important component that is easily overlooked. Most pelvic resections and hemipelvectomies require elevation of the abdominal wall off the bone. After resection, if enough bone remains with acceptable tension, repair should be performed using nonabsorbable suture through drill holes. The presence of a larger defect requires that the gap be spanned with a Gore-Tex sheet or other mesh in order to minimize the risk of herniation of abdominal content. A plastic or general surgeon may be required to assist.

\section{Discussion}

Future directions - computer aided tumor resection. Complex pelvic resections are ideal for computer-aided or navigated assistance, given the proximity of vital structures and the complexity of the bony and soft-tissue anatomy of the region. The addition of intraoperative navigation has the potential to improve the accuracy of the resection margins [23].

Navigation could be useful in cases in which allograft is used in the reconstruction of a pelvic
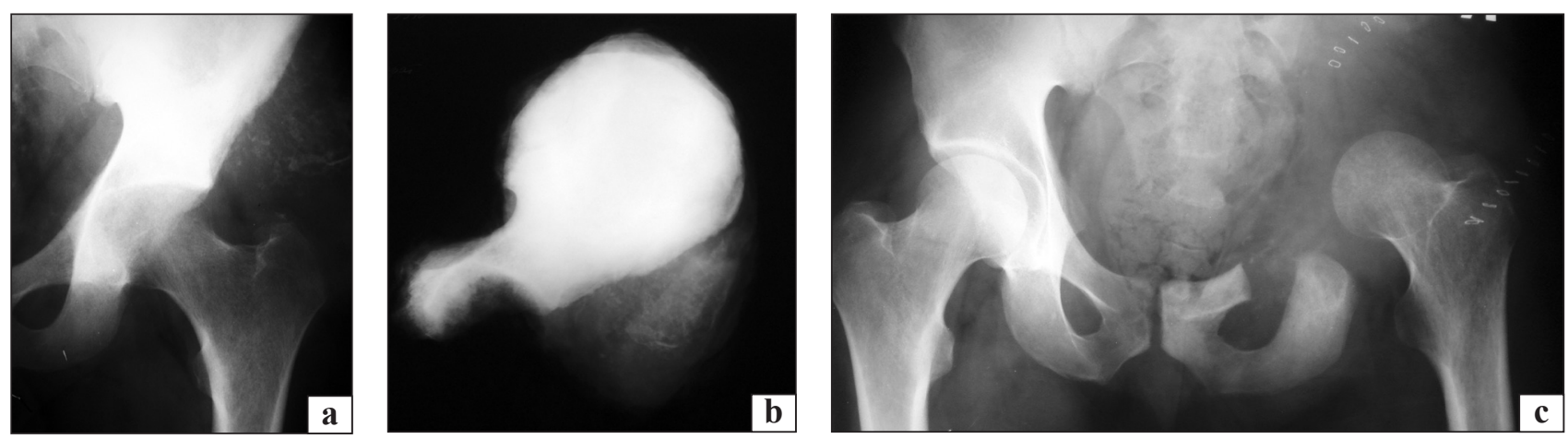

Fig. 7. Illustration of combined type I/II pelvic resection. Male K., 32 y. o., chondrosarcoma (a); resected tumor specimen (b); 5 years after surgery (c) 

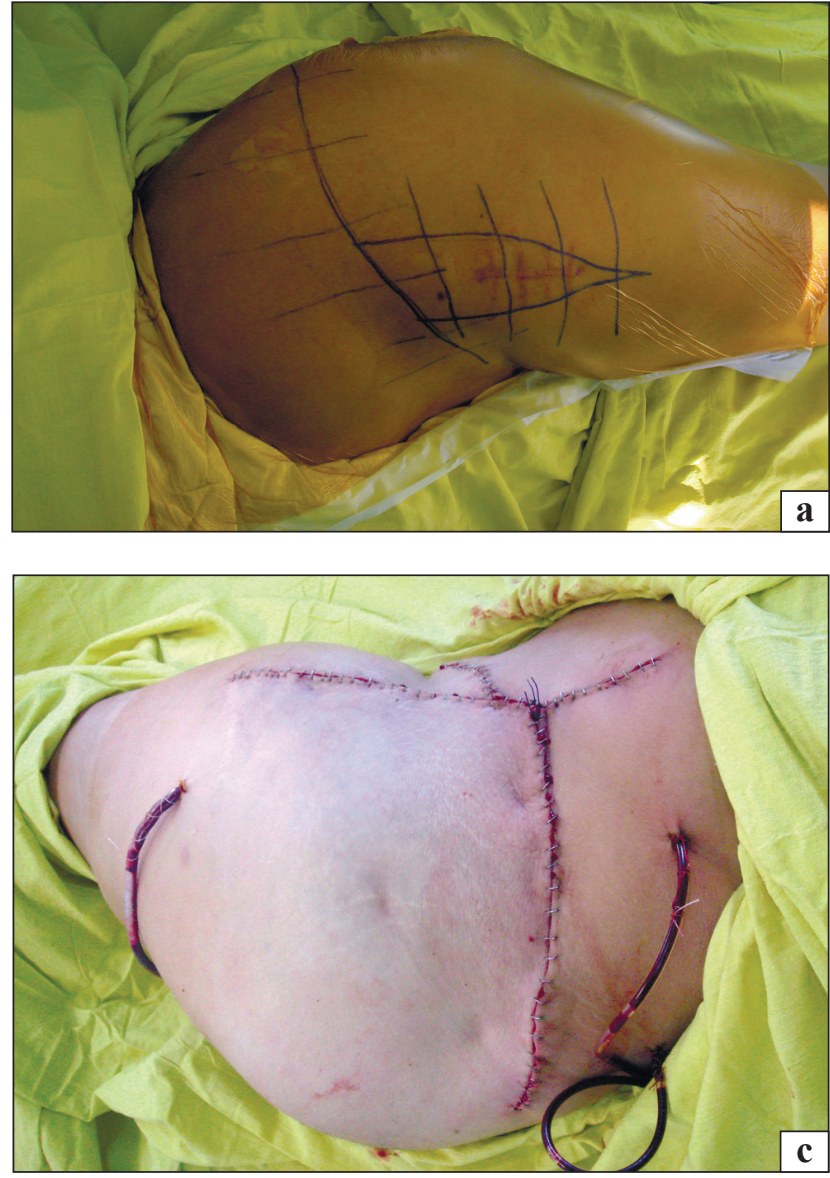

defect. This would allow for precision in size matching and placement of the allograft to the defect as well as in hardware placement, thereby theoretically decreasing the nonunion rate seen in this reconstruction [24].

Although the technological advances in these applications are promising, the indications are evolving and the technology is costly to incorporate and currently is reserved for experimental use at tertiary centers.

Complications. Although the mortality rate associated with hemipelvectomy is relatively low, the rate of associated morbidities is high. The literature regarding complications following hemipelvectomy is limited. The rate of postoperative complications ranges from 20 to $50 \%$ [13, 18, 25-28]. Wound infection and flap necrosis are the most common complications for both hemipelvectomies and pelvic resections [13]. In their examination of the complications of 160 consecutive hemipelvectomies, Senchenkov [28] found increased surgical time and complexity to be associated with increased rates of wound infection and flap necrosis. Flap necrosis was most commonly associated with common iliac vessel ligation. Complication rates for pelvic resections vary
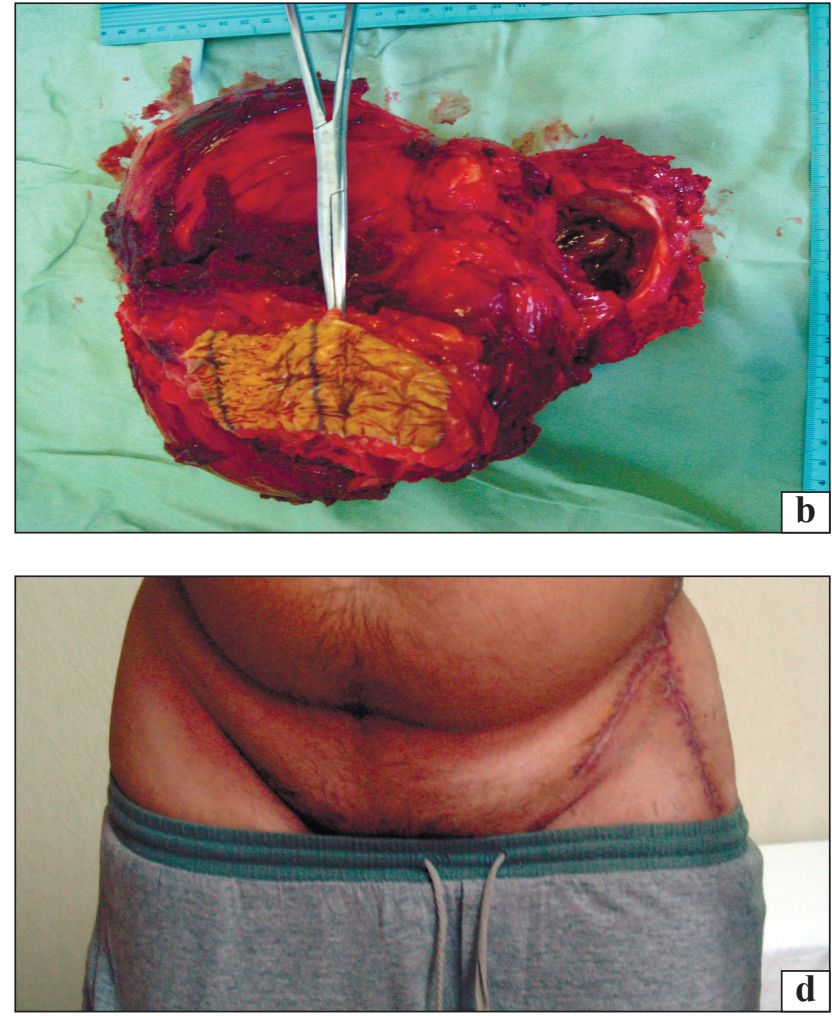

Fig. 8. Illustration of combined type I/II pelvic resection. Male K., 32 y. o., chondrosarcoma. Planning of surgery approach (a); tumor specimen (b); wound closure after surgery (c); stabile pelvic balance 1 year after surgery (d)

based on the complexity of the procedure. In a review of 27 saddle prosthetic reconstructions, Aljassir [18] reported that infection occurred in $37 \%$ of patients. Given the great likelihood of complications associated with hemipelvectomies and pelvic resections, patients should be counseled on the potential predictable complications and negative outcome.

Few studies have addressed the functional outcomes of hemipelvectomies, and there is no standard against which to measure outcome scores. The Medical Outcomes Study 36-item Short Form, TESS, and MSTS are the most commonly used instruments. The TESS and MSTS were originally designed to assess functional outcome following limb salvage of tumors about the knee. There is no validated scoring system for assessing function following pelvic resection, and the TESS and MSTS have been applied empirically to assess function. Especially when performed to address malignancy, both hemipelvectomies and limb salvage pelvic resections lead to decreased functional and quality-of-life outcomes [29]. In a retrospective review, Beck [30] found functional and quality-of-life outcomes to be similar between the 39 patients who underwent pelvic resection and the 58 treated with hemipelvectomy. 
The only statistically significant difference between the pelvic resection and hemipelvectomy groups was that patients with hemipelvectomies had better transfer ability at hospital discharge; however, they also had increased pain and bladder dysfunction at follow-up. Although few patients had independent functional status at discharge, patients in both groups had similar independent function at follow-up. Given the dramatic variability in pelvic tumor cases, however, it is important to note the potential loss of bowel and bladder function; this finding is more common with hemipelvectomy than with pelvic resection. Unfortunately we have not have statisticaly veracious results in all 239 patients of Sytenko Institute group because long period (more then 50 years) follow-up and no significant archive data for patients series. That is why we have use published literature data and results.

\section{Conclusions}

The main indication for pelvic resection (ie, internal hemipelvectomy) and hemipelvectomy is primary malignant tumors of the pelvis; in rare instances, these procedures may be indicated for metastatic lesions, infection, or trauma. The extent of the resection and remaining structures dictates reconstruction options. The current trend is to leave the hip flail; however, successful reconstruction can maintain limb length and maximize function, although it is associated with a higher complication rate. Hemipelvectomies are usually left unreconstructed, but reconstructing the pelvic ring may afford some benefits. Overall, the procedure is technically demanding and requires a thorough knowledge of pelvic anatomy and proximity of vital structures to minimize complications. Appropriate preoperative counseling with the patient and family is paramount to explain the magnitude of the procedure, common complications, and predicted functional loss.

Conflict of interest. The authors declare the absence of conflict of interest.

\section{References}

1. Lee C. M. Hemipelvectomy and hip disarticulation for malignant tumors of the pelvis and lower extremity / C. M. Lee Jr, L. P. Alt // Ann. Surg. - 1953. - Vol. 137 (5). - P. 704-717.

2. Ransohoff J. XIII. Interilio-abdominal amputation: with report of a case / J. Ransohoff // Ann. Surg. — 1909. — Vol. 50 (5). P. 925-935.

3. Internal hemipelvectomy: excision of the hemipelvis with limb preservation. An alternative to hemipelvectomy / F. R. Eilber, T. T. Grant, D. Sakai, D. L. Morton // Cancer. - 1979. Vol. 43 (3). - P. 806-809.

4. Enneking W. E. Resection and reconstruction for primary neoplasms involving the innominate bone / W. E. Enneking, W. K. Dunham // Bone Joint Surg. Am. - 1978. -
Vol. 60 (6). - P. 731-746

5. Cancer statistics, 2010 / A. Jemal, R. Siegel, J. Xu, E. Ward // CA Cancer J. Clin. - 2010. - Vol. 60 (5). - P. 277-300. DOI: 10.3322/caac.20073.

6. Bone cancer/ J. S. Biermann, D. R. Adkins, R. S. Benjamin [et al.] // J. Natl. contpr. cane netw. — 2010. — Vol. 8 (6). P. $688-712$.

7. Spector L. G. Epidemiology of bone and soft tissue sarcomas / L. G. Spector, J. A. Ross, R. Nagarajan // Pediatric bone and soft tissue sarcomas / ed. A. S. Pappo. - New York : Springer, 2006. - P. 1-11.

8. Treatment of advanced metastatic lesions of the acetabulum using the saddle prosthesis / J. Benevenia, F. P. Cyran, J. S. Biermann [et al.] // Clin. orthop. relat. res. - 2004. № 426. - P. 23-31.

9. Damron T. A. Surgical treatment for metastatic disease of the pelvis and the proximal end of the femur / T. A. Damron, F. H. Sim // Instr. course lect. - 2000. - Vol. 49. - P. 461-470.

10. Patient survival after surgery for osseous metastases from renal cell carcinoma / P. P. Lin, A. N. Mirza, V. O. Lewis [et al.] // J. Bone Joint Surg. Am. — 2007. — Vol. 89 (8). P. 1794-1801. — DOI: 10.2106/JBJS.F.00603.

11. Bone metastases from renal cell carcinoma: patient survival after surgical treatment / A. Fottner, M. Szalantzy, L. Wirthmann [et al.] // BMC Musculoskelet. disord. — 2010. — Vol. 11. Article 145. - DOI: 10.1186/1471-2474-11-145.

12. O'Connor M. I. Salvage of the limb in the treatment of malignant pelvic tumors / M. I. O'Connor, F. H. Sim // J. Bone Joint Surg. Am. - 1989. - Vol. 71 (4). - P. 481-494.

13. Complications and outcome of external hemipelvectomy in the management of pelvic tumors / J. P. Apffelstaedt, D. L. Driscoll, J. E. Spellman, [et al.] // Ann. Surg. Oncol. 1996. - Vol. 3 (3). - P. 304-309.

14. Iliosacral resection for primary bone tumors: Is pelvic reconstruction necessary? / G. P. Beadel, C. E. McLaughlin, F. Aljassir, [et al.] // Clin. Orthop. Relat. Res. - 2005. Vol. 438. - P. 22-29.

15. The Friedman-Eilber resection arthroplasty of the pelvis / A. J. Schwartz, P. Kiatisevi, F. C. Eilber [et al.] // Clin. orthop. relat. res. - 2009. - Vol. 467 (11). - P. 2825-2830. DOI: 10.1007/s11999-009-0844-4.

16. Gebert C. Hip transposition as a universal surgical procedure for periacetabular tumors of the pelvis / C. Gebert, G. Gosheger, W. Winkelmann // J. surg. oncol. — 2009. — Vol. 99 (3). P. 169-172. - DOI: 10.1002/jso.21212.

17. Reconstruction using the saddle prosthesis following excision of primary and metastatic periacetabular tumors / A. J. Aboulafia, R. Buch, J. Mathews [et al.] // Clin. orthop. relat. res. 1995. — № 314. — P. 203-213.

18. Outcome after pelvic sarcoma resection reconstructed with saddle prosthesis / F. Aljassir, G. P. Beadel, R. E. Turcotte [et al.] // Clin. Orthop. Relat. Res. — 2005. — Vol. 438. P. 36-41.

19. Harrington K. D. The use of hemipelvic allografts or autoclaved grafts for reconstruction after wide resections of malignant tumors of the pelvis / K. D. Harrington // Bone Joint Surg. Am. - 1992. - Vol. 74 (3). - P. 331-341.

20. Outcome in two groups of patients with allograft-prosthetic reconstruction of pelvic tumor defects / G. P. Beadel, C. E. McLaughlin, J. S. Wunder [et al.] // Clin. Orthop. Relat. Res. - 2005. - Vol. 438. - P. 30-35.

21. Computer-aided custom-made hemipelvic prosthesis used in extensive pelvic lesions / K. R. Dai, M. N. Yan, Z. A. Zhu, Y. H. Sun // Arthroplasty. — 2007. — Vol. 22 (7). - P. 981-986. DOI: $10.1016 /$ j.arth.2007.05.002.

22. Clinical effectiveness of hemipelvic reconstruction using computer-aided custom-made prostheses after resection of malignant pelvic tumors / W. Sun, J. Li, Q. Li [et al.] // 
J. Arthroplasty. — 2011. - Vol. 26 (8). - P. 1508-1513. DOI: $10.1016 /$ j.arth.2011.02.018.

23. New indications for computer-assisted surgery: tumor resection in the pelvis / T. Hufner, M. Kfuri Jr, M. Galanski [et al.] // Clin. Orthop. Relat. Res. — 2004. — № 426. — P. 219-225.

24. Irregular osteotomy in limb salvage for juxta-articular osteosarcoma under computer-assisted navigation / J. Li, Z. Wang, Z. Guo [et al.] / J. Surg. Oncol. — 2012. - Vol. 106 (4). P. 411-416. - DOI: 10.1002/jso.23105.

25. Apffelstaedt J. P. Partial and complete internal hemipelvectomy: complications and long-term follow-up / J. P. Apffelstaedt, D. L. Driscoll, C. P. Karakousis // J. Am. Coll. Surg. - 1995. Vol. 181 (1). - P. 43-48.

26. Hemipelvectomy: a changing perspective for a rare procedure / C. R. Baliski, N. S. Schachar, J. G. McKinnon [et al.] // Can. J. Surg. - 2004. - Vol. 47 (2). - P. 99-103.

27. Proximal major limb amputations: a retrospective analysis of 45 oncological cases / A. Daigeler, M. Lehnhardt, A. Khadra [et al.] // World J. Surg. Oncol. — 2009. — Vol. 7. — Article 15. - DOI: 10.1186/1477-7819-7-15.

28. Predictors of complications and outcomes of external hemipelvectomy wounds: Account of 160 consecutive cases A. Senchenkov, S. L. Moran, P. M. Petty [et al.] // Ann. Surg. Oncol. — 2008. - Vol. 15 (1). - P. 355-363. — DOI: 10.1245/ s10434-007-9672-5/

29. Internal and external hemipelvectomy or flail hip in patients with sarcomas: quality-of-life and functional outcomes / M. J. Griesser, B. Gillette, M. Crist [et al.] // Am. J. Phys. Med. Rehabil. - 2012. - Vol. 91 (1). - P. 24-32. DOI: 10.1097/PHM.0b013e318232885a.

30. Functional outcomes and quality of life after tumor-related hemipelvectomy / L. A. Beck, M. J. Einertson, M. H. Winemiller [et al.] // Phys. Ther. - 2008. — Vol. 88 (8). - P. 916-927. DOI: $10.2522 / \mathrm{ptj} .20070184$.

\title{
КОНЦЕПТУАЛЬНАЯ СТРАТЕГИЯ РЕЗЕКЦИЙ ТАЗА ПРИ ОПУХОЛЯХ
}

\author{
О. Е. Вырва, Р. В. Малык, Я. А. Головина
}

ГУ «Институт патологии позвоночника и суставов им. проф. М. И. Ситенко НАМН Украины», Харьков

Oleg Vyrva, MD, Prof. in Orthopaedics and Traumatology: dr.olegvyrva@gmail.com

$\checkmark$ Roman Malyk: malyk_roman@mail.ua

$\bowtie$ Yanina Golovina, PhD in Orthopaedics and Traumatology: dr.yanina.golovina@gmail.com 